\title{
ASSESSMENT OF BLOOD CHOLESTEROL AMONG STAFF IN KASHIM IBRAHIM COLLEGE OF EDUCATION MAIDUGURI, BORNO STATE, NIGERIA
}

\author{
Maryam Saidu Saleh ${ }^{1}$, \\ Muhammed Wakili Umar Gaya², \\ Abdulsalam, A. ${ }^{2 i}$, \\ Dahiru Abdullahi Dan Asabe ${ }^{3}$ \\ ${ }^{1}$ Kashim Ibrahim College of Education, \\ Maiduguri, Borno State, Nigeria \\ ${ }^{2}$ Department of Physical and Health Education, \\ University of Maiduguri, \\ Maiduguri, Borno State, Nigeria \\ 3Tbrahim Badamasi Babagida University, \\ Lapai, Nigeria
}

\begin{abstract}
:
This study assessed of blood cholesterol among staff in Kashim Ibrahim College of Education Maiduguri, Borno state. Three hypotheses guided the study. Survey research design was used for this study. The population for the study comprised staff of Kashim Ibrahim College of Education Maiduguri numbering 566 (academic staff 216 and nonacademic staff 350). A sample of 57 (males 37, females 20) staff were selected for the study using stratified sampling technique with proportionate method. The instruments used for data collection were floride oxalate container yellow cap and green cap, syringe ( $5 \mathrm{ml})$ with needle to determine blood cholesterol of the participants; biodata sheet was used in recording the information of each participant. Analysis of data was done using descriptive statistics of mean, standard deviation, frequency counts and percentage. $t$ test and Analysis of Variance (ANOVA) was used to test hypotheses at 0.05 alpha level of significance. All the hypotheses formulated was retained. It was concluded that there is no significant difference in the hypotheses tested. Based on the results of this study, it was recommended that adequate sport facilities, including time allocation for sporting activities should be provided by the College authority within the College environment; that will enable the staff to participate in physical activities as a means of preventing the occurrence of these biomedical health risk factors.
\end{abstract}

i Correspondence: email just2abdul@gmail.com 
Keywords: blood cholesterol, staff of Kashim Ibrahim College of Education Maiduguri

\section{Introduction}

Muldoon, Manuck, Mendelsohn, Kaplan and Belle, (2001) defined cholesterol as a fatty substance produced by the liver and carried by the blood to the rest of the body. Its natural function is to provide material for cell walls and for steroid hormones. If levels in the blood are too high, this can lead to the artery-clogging process known as atherosclerosis that can lead to heart attack, angina or stroke. The body needs cholesterol to function normally. However, individual's body makes all the cholesterol it needs. Over a period of years, extra cholesterol and fat circulating in the blood build up in the walls of the arteries that supply blood to the heart. This buildup, called plaque, makes the arteries narrower and narrower.

As a result, less blood gets to the heart. Blood carries oxygen to the heart; if enough oxygen-rich blood cannot reach the heart, the individual may suffer chest pain. If the blood supply to a portion of the heart is completely cut off, the result is a heart attack. Cholesterol travels in the blood in packages called lipoproteins. Low Density Lipoproteins (LDL) carries most of the cholesterol in the blood. Cholesterol packaged in LDL is often called bad cholesterol, because of too high level of LDL in the blood can lead to cholesterol buildup and blockage in one's arteries. (Muldoon, et al. 2001)

Another type of cholesterol is High Density Lipoprotein (HDL), also called good cholesterol. That's because HDL helps remove cholesterol from the body, preventing it from building up in the arteries. The risk of heart disease increases steadily from a low base with increasing blood cholesterol levels. Blood cholesterol level of $5.5 \mathrm{mmol} / \mathrm{L}$ or more is considered 'high' but this is an arbitrary definition. Cholesterol is a fatty substance produced by the liver and carried around the body by the blood. Having high cholesterol is a risk factor that is known to contribute to the development of chronic diseases, such as ischemic heart disease and stroke.

\section{Hypotheses}

Ho1: There is no significant difference in blood cholesterol between male and female staff of Kashim Ibrahim College of Education Maiduguri.

Hoz: There is no significant difference in blood cholesterol among staff of different age groups in Kashim Ibrahim College of Education Maiduguri.

Ноз: There is no significant difference in blood cholesterol between academic and non-academic staff in Kashim Ibrahim College of Education Maiduguri.

\section{Methodology}

Survey research design was used for this study. A survey is a method of research that involves the characteristics of individuals, groups, objects or situation. Survey research 
method is concerned with the collection of data for the purpose of describing and interpreting existing conditions or practice, beliefs, attitudes and so on. Survey design, according to Thomas and Nelson (1990) is a technique that seeks to determine the practices or opinions of a specified population on one or more variables. Corner and Norman (2004) stated that the purpose of survey research method is to describe systematically the facts, qualities or characteristics of a given population, event or area of interest concerning the problem under investigation. The use of this design was considered appropriate because of its importance which suits a study of this nature that sought to determine the prevalence of biomedical health risk factors among staff of Kashim Ibrahim College of Education Maiduguri.

The population for this study comprised five hundred and sixty six (566) staff of Kashim Ibrahim College of Education Maiduguri (KICOE Establishment Unit, 2015). Out of this population two hundred and sixteen (216) were academic staff comprising 77 females and 139 males, and three hundred and fifty (350) non-academic staff comprising 119 females and 231 males. Stratified sampling technique with proportionate method was used to sample ten percent $(10 \%)$ of the population for the study. Ten percent $(10 \%)$ of the entire population is 56.6 which was approximated to 57 because fractions of human beings cannot be obtained. Twenty-two (22) academic staff comprising 8 females and 14 males, and thirty-five (35) non-academic staff comprising 12 females and 23 males were selected for the study. The selection of the sample was based on Krejie and Morgan (1979) who stated that in a large population, ten percent $(10 \%)$ will be appropriate. Cost implication and the willingness of the participants to partake in the study, which involved taking blood sample was taken into consideration for the selection of 10 percent of the population as a sample.

The research instruments used in collecting data for this study were as follow: floride oxalate container (yellow cap), syringe $(5 \mathrm{ml})$ with needle (made in USA 2016 model), and Buffer of Lyophelized enzymes, hydrogen peroxidase, blank standard solution and test solution were used to determine blood cholesterol of the participants.

An introductory letter containing the purpose of the research was obtained from the Head of Department, Physical and Health Education of the University of Maiduguri to the Registrar, Kashim Ibrahim College of Education Maiduguri for permission to conduct the research in the college. After obtaining the permission from the college authority the participants were briefed by the researcher about the testing procedures and it benefits. The researcher provided biodata sheet to record the age, sex, tag number, glucose level, cholesterol level, height and weight of the participants. Fifty seven tags numbering from $01-57$ were provided for easy identification of the participants. The participants came up for the testing exercise in the morning 7.30 to 9:00am at the college clinic. Two (2) trained research assistants were used to assist the researcher in data taking, a trained Nurse took the blood pressure, height and weight of the participants. 


\subsection{Determination of Blood Cholesterol}

To determine the cholesterol level of the participants, participants fasted for about twelve hours and the same procedure for determining fasting blood glucose was used. Collection of blood was done from the cephalic vein (located at the upper arm) with $5 \mathrm{ml}$ syringe and needle and the blood was put into a green cap floride oxalate container, then it was centrifuged. Only the plasma was used for estimation. The methodology used was enzymatic method. The reagent used were buffer, lyopolized enzymes to get cholesterol oxidase, cholesterol esterase and standard solution at $200 \mathrm{mg} / \mathrm{dl}$ or $5.17 \mathrm{mmol} / \mathrm{dl}$. The powdered reagents were added into the Buffer, $2 \mathrm{ml}$ in the blank, $2 \mathrm{ml}$ in the standard with $20 \%$ of standard solution in the standard and $2 \mathrm{ml}$ adding $20 \%$ of solution to the plasma test. It was mixed and incubated at $37^{\circ} \mathrm{C}$ (degree centigrade) for 15 minutes using water bath. It was read at wavelength $520-530 \mathrm{~mm}$. It was read using spectrophotometer. The blank was read first to set the instrument at 0.00 observant. Read standard at 0.11 , the test at 0.10 , the cholesterol was then determined at $5.0 \mathrm{mmol} / \mathrm{dl}$ as normal level (White, 2016). Descriptive statistics of mean, standard deviation, frequency counts and percentage were used to describe the biodata of the participants and answer research questions. One-way ANOVA and t-test were used to test hypotheses. All hypotheses were tested at 0.05 alpha level of significance.

\section{Results}

Table 1: Demographic Variables of the Participants $(n=57)$

\begin{tabular}{|l|c|c|}
\hline Variable & Frequency & Percentage \\
\hline Age (Years) & & 14.0 \\
\hline $20-30$ & 13 & 22.8 \\
\hline $31-40$ & 19 & 33.3 \\
\hline $41-50$ & 14 & 24.5 \\
\hline $51-60$ & 3 & 5.26 \\
\hline 61 above & & \\
\hline Sex & 37 & 64.9 \\
\hline Male & 20 & 35.1 \\
\hline Female & & \\
\hline Staff Cadre & 22 & 38.6 \\
\hline Academic Staff & 35 & 61.4 \\
\hline Non-Academic Staff & & \\
\hline
\end{tabular}

Table 1 contains the demographic variables of the participants. Three variables were displayed in the table namely age, sex and staff cadre. Breakdown of age brackets shows that there were $8(14.0 \%)$ participants aged 20 - 30 years, $13(22.8 \%)$ aged $31-40$ years. Those in age bracket of 41 - 50 years were 19 (33.3\%), those within the age bracket of 51 - 60 years were $14(24.5 \%)$ and participants aged 61 and above years were $3(52.6 \%)$. This means that most of the participants were between the age bracket of $41-50$ years 19 (33.3\%) followed by age bracket 51 - 60 years 14 (24.5\%), then age bracket $31-40$ years 
$13(22.8 \%)$, and age bracket 20 - 30 years $8(14.08)$, lastly age bracket 61 and above years $3(52.6 \%)$.

With regards to sex of the participants 37 (64.9\%) were males, while $20(35.1 \%)$ were females. This means that most of the participants were males $(64.9 \%)$. With regard to staff cadre, 22 (38.6\%) were academic staff while $35(61.4 \%)$ of the participants were non-academic staff. This means that most of the participants were non-academic staff.

Ho1: There is no significant difference in blood cholesterol between of male and female staff of Kashim Ibrahim College of Education Maiduguri.

Table 2: Summary of t-test on Blood Cholesterol of Male and Female Staff of Kashim Ibrahim College of Education Maiduguri $(\mathrm{mml} / \mathrm{l})(\mathrm{n}=57)$

\begin{tabular}{|l|c|c|c|c|c|}
\hline Participants & Number & $\overline{\mathbf{x}}$ & $\mathbf{s}$ & $\mathbf{T}$ & P. Value \\
\hline Male & 37 & 4.3978 & \pm .40232 & \multirow{2}{*}{1.438} & 0.156 \\
\hline Female & 20 & 4.6060 & \pm .69336 & \\
\hline
\end{tabular}

Table 2 contains information on blood cholesterol of male and female staff of Kashim Ibrahim College of Education Maiduguri. t-test was applied to test the null hypothesis at 0.05 alpha level. The result indicated that there was no significant difference in blood cholesterol between male and female staff of Kashim Ibrahim College of Education Maiduguri $(\mathrm{P}>0.05)$, therefore the null hypothesis was retained.

Ho2: There is no significant difference in the blood cholesterol among staff of different age groups in Kashim Ibrahim College of Education Maiduguri.

Table 3: Summary of One-Way ANOVA on Blood Cholesterol of Staff of Different Age Groups in Kashim Ibrahim College of Education Maiduguri ( $n=57)$

\begin{tabular}{|l|c|c|c|c|c|}
\hline Sources of Variance & Sum of Squares & df & Mean squares & F & P. Value \\
\hline Between groups & 2.005 & 4 & .501 & \multirow{2}{*}{1.740} & 0.155 \\
\hline Within groups & 14.965 & 52 & .288 & & \\
\hline Total & 16.970 & 56 & & \\
\hline
\end{tabular}

Table 3 shows the summary of one-way ANOVA on blood cholesterol of staff of different age groups in Kashim Ibrahim College of Education Maiduguri. One-way ANOVA was applied to test the null hypothesis at 0.05 alpha level. The result showed that there was no significant difference in blood cholesterol among staff of different age groups in Kashim Ibrahim College of Education Maiduguri $(P>0.05)$, hence the null hypothesis was retained. Therefore, the null hypothesis was accepted.

Ноз: There is no significant difference in blood cholesterol between academic and non-academic staff of Kashim Ibrahim College of Education Maiduguri. 
Table 4: Summary of t-test on Blood Cholesterol (mmol/l) of Academic and Non-Academic Staff of Kashim Ibrahim College of Education Maiduguri $(n=57)$

\begin{tabular}{|l|c|c|c|c|c|c|}
\hline Staff Cadre & Number & $\mathbf{~}$ & $\mathbf{~}$ & $\mathbf{d f}$ & $\mathbf{t}$ & P. Value \\
\hline Academic Staff & 22 & 4.615 & \pm .66891 & 55 & 1.356 & 0.181 \\
\hline Non-academic Staff & 35 & 4.408 & \pm .47117 & & & \\
\hline
\end{tabular}

Table 4 contains information on blood cholesterol of academic and non-academic staff of Kashim Ibrahim College of Education Maiduguri. t-test was applied to test the null hypothesis at 0.05 alpha level. The result showed that there was no significant difference in blood cholesterol of academic and non-academic staff of Kashim Ibrahim College of Education Maiduguri ( $\mathrm{P}>0.05)$, hence the null hypothesis was retained, that is the null hypothesis was accepted.

\section{Discussion}

Ravnskov (2002) carried out a cohort study of 9147 individuals, but the investigators selected only 127 (14\%) for the purpose of studying cholesterol, though it was not a random selection and the report did not describe the selection criteria $10 \%$ of the individuals were found to have high blood cholesterol, of 5 to $6 \mathrm{mmol} / \mathrm{l}$ range. Two studies from Japan by Marmot (1975) claimed a positive correlation, but correlation coefficients were even smaller than in the Framingham study, and in one study the correlation appeared only in individuals with low or normal cholesterol levels, and in the other only in the elderly. In a study from Norway carried out by Song, Sung and Kim (2000), it was shown that arteries had cholesterol levels as high as those for whom all the three coronary vessels were constricted, and those with two constricted vessels had lower levels than those with just one constricted artery.

When cholesterol levels are too high there is risk for developing a blockage to the heart and it will result to heart diseases, heart attack or dying of heart diseases (Lasky, Beccrra, Boto, Otim \& Ntambi, 2002). Cholesterol lowering is important for everyone younger, middle age and older adults; women and men; and people with or without heart disease. This is because in general, the higher the LDL level the more risk factors an individual will have, the greater the chances of developing heart disease or having a attack. Some people are at high risk for a heart attack because they already have heart disease. Other people are at high risk for developing heart disease because they have hypertension and diabetes (which are strong risk factors to health) or combination of risk factors for heart disease (www.nutrition.gov). There are major risk factors that affect the LDL goal if proper care is not taken, because it can trigger the risk to heart disease and heart attack. Factors such as cigarette smoking, high blood pressure $(140 / 90 \mathrm{mmHg}$ or higher or on blood pressure medication). Low HDL cholesterol (less than $40 \mathrm{mg} / \mathrm{dl}$ ), family history of early heart disease (heart disease in father or brother before age 55; heart disease in mother or sister before age 65), and age (men 45 years or older, women 55 years or older) all these affect an individual's cholesterol level and health (www.healthfinder.gov). 
In Ghana, earlier studies revealed a cholesterol prevalence of $4.5 \%$ among rural dwellers while in Nigeria the prevalence of high cholesterol was found to be $10 \%$ in rural areas (Aspray, Mugusi and Rashid, 2000). A generally favourable lipid profile (low total and low-density cholesterol, and normal to high density cholesterol) and low homocysteine values have been reported among the general population in Africa (Swei, McCarty and Kitange, 1993). However, hyperlipidaemia is becoming increasingly common and studies from Tanzania observed $25 \%$ prevalence elevated serum total cholesterol (Cholesterol greater than $5.2 \mathrm{mmol} / \mathrm{l}$ and $15 \%$ prevalence of elevated triglycerides (less than $1.7 \mathrm{mmol} / \mathrm{l}$ ) among adults over 35 years of age, with women being affected more than men (Njelekela, Negishi and Nara, 2001).

Lasky, Becerra, Boto, Otim and Ntambi (2002) found that the estimated prevalence of cholesterol in sub-Saharan Africa is about 1\% in rural areas and $5-7 \%$ in urban areas, and between $8 \%$ and $13 \%$ in countries like Uganda and South Africa. Nigeria is a multiethnic nation organized into six geo-political zones inhabited by people with diverse cultures. Most of the rural communities are inhabited by children, men and women who belong more to the low socioeconomic strata. Most of the men and women are elderly people who have retired from active service. Most active youths and middle-aged individuals resides in the urban and semi-urban cities characterized by better social amenities and job opportunities. Prevalence of high blood cholesterol tend to be low in rural communities due to the traditional lifestyle the inhabitants are thought to adopt, but is common in urban and semi-urban communities (Pobee, 1993).

\subsection{Recommendation}

Based on the conclusion of this study, the following recommendations were made: Adequate sport facilities, including time allocation for sporting activities should be provided by the College authority within the College environment; that will enable the staff to participate in physical activities as a means of preventing the occurrence of these biomedical health risk factors.

\section{References}

Aspray, T. J., Mugusi, F. \& Rashid, S. (2000). Rural and Urban Differences in Diabetes Prevalence in Tanzania: The Role of Obesity, Physical Inactivity and Urban Living, transactions of the royal society of tropical medicine and hygiene, vol. 94, no. 6 . pp. $637-644$.

Corner, M. \& Norman, P. (2004). Predicting Health Behaviour: Search and Practice with Social Cognition Models; Ballmore. Buckingham, Open University Press.

MyHealthfinder I health.gov. https://health.gov/myhealthfinder.

Nutrition.gov I USDA. https://www.nutrition.gov/.

Krejie \& Morgan (1979). Handbook of research on educational psychology. New York: Macmillan. 
Lasky, D., Becerra, E., Boto, W., Otim, M. \& Ntambi, (2002). Obesity and gender differences in the risk of type 2 diabetes mellitus in Uganda, Nutrition, Vol. 18, no 5. Pp. $417-421$.

Marmot, P. H. (1975). Prevalence of High Blood Pressure among two Communities in India: Journal of Medical Health. 5(5): 148 - 152.

Muldoon, M. F., Manuck, S. B. Mendelsohn, A. B., Kaplan, J. R. \& Belle, S. H. (2001). Cholesterol reduction and non-illness mortality: meta-analysis of randomized clinical trials. British Medical Journal, 322:11-15.

Njelekela, M., Negishi, H. \& Nara, Y.(2001). Cardiovascular risk factors in Tanzania: a revisit, Acta Tropica, Vol. 79. No. 3, pp. $231-239$.

Pobee, J. O. (1993). Community-based high blood pressure programs in Sub-Saharan Africa, Ethnicity and Disease, Vol 3 Supplement, pp. $538-545$.

Ravnskov, U. (2002). LDL-C does not cause cardiovascular disease: a comprehensive review of the current literature. The American Journal of Clinical Nutrition, Volume 84, Issue 6, 1551-1552, https://doi.org/10.1093/ajcn/84.6.1551.

Song, I., Sung, S. H. \& Kim, H. C. (2000). Low Serum Cholesterol and Hemorrhagic Stroke in Meu. Korea Medical Corporation Study. The Lancet, 357: 922 - 925.

Swai, A. B. M., McLarty, D. G. \& Kitange, H. M. (1993). Low prevalence of risk factors for coronary heart disease in rural Tanzania. International Journal of Epidemiology, vol. 22, no. 4, pp. $651-659$.

Thomas, J. R. \& Nelson, J. K. (1990). Research Methods in Physical Activity. Illinois: Human Kinetics Books.

White, M. R. (2016). Ken. Medical Laboratory. Maiduguri Opp. Bank of the North Street, Post Office. Borno State, Nigeria.

Your guide to lowering High Blood Pressure (www.nhlbi.nih.gov/hbp). 

to copy, distribute, transmit or adapt the article content, providing a proper, prominent and unambiguous attribution to the authors in a manner that makes clear that the materials are being reused under permission of a Creative Commons License. Views, opinions and conclusions expressed in this research article are views, opinions and conclusions of the author(s). Open Access Publishing Group and European Journal of Social Sciences Studies shall not be responsible or answerable for any loss, damage or liability caused in relation to/arising out of conflicts of interest, copyright violations and inappropriate or inaccurate use of any kind content related or integrated into the research work. All the published works are meeting the Open Access Publishing requirements and can be freely accessed, shared, modified, distributed and used in educational, commercial and non-commercial purposes under a Creative Commons Attribution 4.0 International License (CC BY 4.0). 